\title{
O CONCEITO DE PRAÇA PARA A QUALIDADE DA PAISAGEM URBANA
}

\author{
EL CONCEPTO DE PLAZA PARA LA CALIDAD DEL PAISAGE URBANO
}

\section{THE CONCEPT OF SQUARE TO THE QUALITY OF URBAN LANDSCAPE}

\section{ECKER, VIVIAN DALL'IGNA}

Mestre em Urbanismo, História e Arquitetura da Cidade (PGAU-Cidade/UFSC), vivianecker@gmail.com

\section{RESUMO}

As praças são uma tipologia decorrente da cultura urbana de origem europeia, e que está associada à imagem de espaço livre, cercado de edificações. São espaços públicos presentes em muitas cidades, desde as suas origens, e possuem qualidades arquitetônicas e paisagísticas que Ihes denotam a característica de espaço de convergência e centralidade. Nesta pesquisa, parte-se do pressuposto de que, a partir de determinados atributos, as praças incentivam as práticas de sociabilidade, fortalecendo o senso de identidade e pertencimento dos habitantes às cidades. Da mesma forma, a partir de atributos ambientais e paisagísticos, estas contribuem para a qualidade da paisagem urbana. Com base nos pressupostos apresentados, pretende-se expor, neste artigo, uma revisão bibliográfica acerca da qualidade espacial de praças, descrevendo os principais conceitos relativos a esta tipologia. A sistematização das informações contou com a leitura, a análise e a interpretação de diferentes fontes, que serviram de fundamentação teórica, para os resultados alcançados.

PALAVRAS-CHAVE: praças; qualidade espacial; conceitos.

\section{RESUMEN}

Las plazas son una tipología que decorre de la cultura urbana de origen europea, y que se asocia con la imagen del espacio libre, circundado de edificaciones. Son espacios públicos presentes en muchas ciudades, desde sus orígenes, y tienen cualidades arquitectónicas y paisajísticas que les denotan características de convergencia y centralidad. En esta investigación, se supone que, a partir de ciertos atributos, las plazas fomentan las prácticas de sociabilidad, fortaleciendo el sentido de identidad y pertenencia de los habitantes a las ciudades. Del mismo modo, por sus atributos ambientales y paisajísticos, estas contribuyen a la calidad del paisaje urbano. Con base en los supuestos presentados, pretendemos exponer, en este artículo, una revisión bibliográfica acerca de la calidad espacial de plazas, describiendo los principales conceptos relacionados a esta tipología. La sistematización de la información se basó en la lectura, el análisis y la interpretación de diferentes fuentes, que sirvieron de fundamentación teórica para los resultados obtenidos.

PALABRAS CLAVE: plazas; calidad espacial; conceptos.

\section{ABSTRACT}

The squares are a typology that has origin in the european urban culture, and that are associated with the image of an open space, surrounded by buildings. They are public spaces that have been present in many cities since their origins, and have architectural and landscape qualities that denote characteristics of convergence and centrality. In this research, it is assumed that, departing from certain attributes, the squares encourage sociability practices, strengthening the sense of identity and belonging into cities inhabitants. Also, from their environmental and landscape attributes, they contribute to the quality of the urban landscape. Based on the assumptions presented, it is intend to expose, in this article, a bibliographical review about the spatial quality of squares, describing the main concepts related to this typology. The information systematization relied on the reading, analysis and interpretation of different sources, which served as theoretical basis for the results achieved.

KEYWORDS: squares; spatial quality; concepts. 


\begin{abstract}
O ambiente urbano é caracterizável pelo conjunto de práticas exercidas cotidianamente nos mesmos lugares da cidade, entretanto, os eventos observados nos espaços públicos assumem sempre um destaque especial pelo seu caráter de espaço de uso coletivo. Os pesquisadores da história da cidade atestam sua permanência no tempo. A organização das práticas urbanas no território explica a forma e a estrutura dessa ocupação, e a organização física da cidade retrata sua função básica como dispositivo de interação e sociabilidade (VAZ, 2010, p. 29).
\end{abstract}

Espaço público, esfera pública, vida pública, domínio público, são termos utilizados para conceituar os espaços de uso coletivo nas cidades, nos quais ocorrem as práticas de sociabilidade (ARENDT, 2007; HABERMAS, 1984; SENNET, 1993; VAZ, 2010; REIS FILHO, 2006). Espaço aberto, espaço externo, espaço coletivo, espaço livre, área aberta, áreas livre, área verde e ambiente externo, são termos correlatos, utilizados para designar qualquer espaço aberto que se situe fora da edificação (MAGRO, 2006). $\mathrm{Na}$ conceituação do termo público, Vaz (2010, pág. 27), apresenta àquela constante em dicionários, como sendo "o que concerne à coletividade em seu conjunto ou que dela emana por oposição a privado, aquilo que é do uso de todos ou acessível a todos". Em algumas cidades, os espaços públicos chegam a ocupar $40 \%$ do tecido urbano. São considerados espaço público urbano as ruas, vielas, avenidas, boulevares, largos, praças, jardins, parques, passeios, esplanadas, cais, pontes, praias, mar, rios, suas margens e canais, caracterizados como lugares abertos e acessíveis a toda a população (MENEZES, 2013).

Do ponto de vista da sociabilidade, o espaço público é todo espaço que se configura como local de estímulo ao convívio e às oportunidades de interação social. O espaço público realiza a mediação entre os usuários, absorvendo os conflitos entre público e privado, indivíduo e multidão, liberdade individual e necessidades coletivas (OLIVEIRA, 2013). Para Carr et al (1995, p.03), "esses espaços dinâmicos (as ruas, praças e parques) são uma contrapartida essencial para as rotinas preestabelecidas do trabalho e da vida doméstica, fornecendo as possibilidades diárias de movimento, as oportunidades de comunicação e os locais compartilhados para a recreação e o descanso".

O conceito de espaço público urbano compreende os espaços abertos da cidade, os lugares acessíveis à livre frequentação, à passagem de cidadãos e à comunicação entre diferentes atores em um ambiente público (VAZ, 2010). A configuração do espaço público atua na organização social, expressando, refletindo, viabilizando e até condicionando as práticas sociais (JACOBS, 2001). O espaço público suaviza a fronteira entre estar sozinho e acompanhado, favorece a liberdade, e permite que se esteja com outras pessoas sem estar com alguém especificamente, devido ao anonimato e à distância pública que oferece (GEHL, 2010).

Em sua configuração, os espaços públicos possuem uma série de espaços e elementos urbanos, que darão suporte às suas atividades. A qualidade do espaço público está relacionada à diversidade de configurações e de atividades que este possui, e que estimularão diferentes usuários em distintos horários (crianças, jovens, adultos, idosos). Jacobs (2001) advoga por espaços bem conectados e densamente povoados, onde as pessoas se sintam seguras com a presença de outras pessoas. Afirma que a presença de pessoas e suas atividades são atributos de fundamental importância para garantir a qualidade do espaço público. No que concerne às atividades, pode-se dizer que um espaço público ideal possui: pessoas passando o tempo todo; pessoas permanecendo; pessoas se encontrando, de forma não programada e programada; pessoas mantendo e vigiando, formal e informalmente; pessoas realizando diversas atividades (TENÓRIO, 2012).

De acordo com Vaz (2005), dentre os espaços públicos urbanos, a praça desempenha um papel particular, que Ihe atribui a condição privilegiada de centralidade urbana, com caráter permanente no desenvolvimento das cidades. A formação de uma centralidade é decorrente da instalação de um uso atrativo, tal como comércio ou outros, de modo a exercer um efeito polarizador no entorno urbano. As centralidades urbanas promovem a construção da identidade social. A identidade social, como senso de pertencimento, é uma elaboração imaginária que se fundamenta em traços, hábitos, características pessoais e acontecimentos comuns ao conjunto da população, produzindo reconhecimento individual e coesão social (PESAVENTO, 2007). É formada pela memória coletiva, e evoca significados que transformam determinados espaços urbanos em referências espaciais. As centralidades urbanas atuam como elementos articuladores, que contribuem para o ordenamento da cidade.

O termo 'praça' deriva do latim platea - rua larga -, designando na linguagem coloquial do Brasil um tipo particular de espaço público urbano - uma forma arquitetônica aberta. Podese observar o sentido comum nas línguas neolatinas, nas quais o termo 'praça pública' designa um lugar descoberto, uma área livre cercada de edificações e emoldurada por suas fachadas, as quais estabelecem os limites e, ao mesmo tempo, contêm as aberturas para o espaço exterior (VAZ, 2010, p. 233). 
Praça, piazza, plaza, place, platz, square, e termos semelhantes. Praça (do grego platéia - "rua larga"): lugar público cercado de edifícios; largo; mercado; feira (FERREIRA, 1986). A praça é um componente presente em muitas das cidades ocidentais, independentemente de qual seja a nacionalidade, ou os valores culturais. É um espaço público, de uso coletivo que, desde que proposto, passou a ser apropriado a qualquer cidade, pelo homem fundada. Inicialmente compreendida como o espaço público da cultura, da política e da vida social, com o passar do tempo esta passou a ser conceituada como o local no qual ocorrem as mais diversas atividades - sociais, comerciais, culturais, recreativas, esportivas. Em um determinado período, a praça, que era meramente utilizada como um espaço para a realização das atividades humanas, passou, também, a incorporar, em seu desenho, qualidades arquitetônicas e paisagísticas de suma importância, na história das cidades. Atualmente, não há cidade que não possua uma praça referencial, que configure-se como um espaço de convergência e centralidade.

Para a cultura ocidental, as praças têm desempenhado um papel essencial: toda cidade possui uma praça que se destaca como símbolo urbano, palco de eventos históricos, espaço referencial (SITTE, 1992). Na configuração de muitas cidades, a praça define uma ruptura no conjunto edificado de seu entorno urbano, definindo um ponto nodal para as práticas de sociabilidade. Diante deste contexto, as praças são tidas como locais com configuração singular, de grande valor simbólico, que possuem caráter de centralidade, e sustentam um patrimônio rico em história e tradição sobre a cidade (MARX, 1991).

De acordo com Vaz (2010), podendo-se interagir com outras pessoas, ou não, a praça gera um estimulo ao convívio, ao defrontar-se, publicamente, com a presença do outro. Constituindo-se um espaço público por excelência, a praça padroniza gestos, posturas e atitudes, que estimulam uma série de ações coletivas, e permitem estabelecer relações de vizinhança, definindo comportamentos de proximidade, ou distanciamento. Cordialidade, polidez, civilidade, são algumas das relações estabelecidas nos espaços da praça que, por suas características, contribuem para o exercício da sociabilidade. Constituindo-se um espaço público por excelência, a praça possibilita, ainda, estabelecer não apenas relações do indivíduo com o outro, mas também com o lugar. Elementos de mobiliário urbano, arte pública, sinalização, iluminação e pavimentação contribuem para ambientá-la, e torná-la propícia ao uso. Ajardinamentos qualificam, ainda, os seus espaços, contribuindo significativamente para a melhoria da qualidade da paisagem urbana.

Com vistas ao pleno entendimento do conceito de praça e de seus desdobramentos, este trabalho resulta de uma pesquisa bibliográfica que, a partir de autores referenciais, sistematizou os conceitos, que serão apresentados neste artigo. Adotou-se o método de consulta à documentação, obtendo-se informações em livros, periódicos, artigos, teses e páginas eletrônicas, relacionados aos autores em estudo. A sistematização das informações contou com a leitura, a análise e a interpretação de diferentes fontes, que serviram de fundamentação teórica, para os resultados alcançados. Em seu desenvolvimento, inicialmente, será apresentado o conceito de praça. A seguir, serão apresentados os conceitos relacionados à sua qualidade espacial

\title{
2. DESENVOLVIMENTO
}

\begin{abstract}
As praças são formadas por um conjunto integrado de recantos cuja função é definida pelo uso predominante. A acolhida das configurações cênicas é diferente em cada recanto da praça, resultando das características espaciais de cada um deles. Essas qualidades estão ligadas à conformação do espaço e da paisagem, predispondo a ocorrência em maior ou menor grau das configurações cênicas. A área sombreada pelas árvores, os bancos distribuídos em torno de um espaço livre e limpo, a iluminação durante o dia e à noite criam o ambiente convidativo ao ator e ao espectador, o desfile constante de transeuntes encontra a sua "passarela" (VAZ, 2010, p. 223).
\end{abstract}

Para Caldeira (2007), a praça sustenta um patrimônio rico em história e tradição sobre a cidade, configurando-se como um local de identidade cultural, com elevado conteúdo simbólico. Tomada como espaço referencial, a praça pode ser considerada como um dos espaços públicos mais adequados à sociabilidade. De acordo com Simmel (1917), a sociabilidade é conceituada como "a forma na qual os indivíduos, em razão de seus interesses - sensoriais, ideais, momentâneos, duradouros, conscientes, inconscientes, movidos pela causalidade ou teologicamente determinados - se desenvolvem conjuntamente, em direção a uma unidade onde esses interesses se realizam - formando a base da sociedade humana". Especializada nessa função, a praça fornece os indícios das qualidades arquitetônicas e paisagísticas necessárias à interação dos cidadãos no cotidiano da vida urbana (VAZ, 2005). 
De acordo com Vaz (2010), as praças são os espaços públicos nos quais ocorrem os encontros do cotidiano, e que possuem qualidades arquitetônicas e paisagísticas, que favorecem a interação social. Estas qualidades podem ser traduzidas em uma série de ambiências, cujo ordenamento estará relacionado às características de cada um de seus espaços, e às atividades que, nele, ocorrerão. Segundo o autor, o termo praça deriva do latim platea (rua larga), designando, na linguagem coloquial do Brasil, um tipo particular de espaço público - uma forma arquitetônica aberta. Para ele, o caráter da praça é sugerido por um conjunto de atributos, organizados em determinada disposição cenográfica: nas praças, a diversidade de eventos (composta por atividades, cenas de encontro, grupos a conversar, indivíduos a olhar o movimento) constituem referências que confirmam a sua centralidade, e caracterizam a sua vocação como um espaço urbano referencial - ponto nodal, espaço de convergência (VAZ, 2010). Complementando a sua abordagem, autores referenciais também discorrem sobre o conceito de praça:

- De acordo com Sitte (1992), a praça, na cidade tradicional, bem como a rua, estabelecia estreita relação do espaço livre com o conjunto edificado envolvente (os planos marginais e as fachadas as edificações), organizando o cenário urbano. Revelava uma arquitetura de grande apuro, onde se concentravam os principais edifícios da cidade, oficiais ou religiosos, ficando os demais em um plano de inferior importância. Por esta razão, no perímetro das praças se edificavam as instituições referenciais (tais como igrejas, palácios governamentais, câmaras legislativas, fóruns).

- Lynch (2011) define que as praças são espaços onde proporcionar o bem-estar dos indivíduos é o principal objetivo. Em relação à morfologia urbana, sobretudo por preencher o tecido urbano com seu caráter de espaço plurifuncional, as praças atuam como referência espacial na paisagem conformada pelas edificações. Por funcionarem como pontos nodais no tecido urbano, contribuem para a apropriação social dos espaços da cidade.

- Para Mascaró (1996; 2007), a praça é um espaço livre, de uso coletivo, que possui funções urbanas e arquiteturas significativas. É um local com configuração singular, delimitada pelas fachadas das edificações que a circundam, compreendida como uma subtração no conjunto edificado. Nela, a vegetação, o mobiliário, a infraestrutura, os equipamentos, a iluminação pública, os percursos peatonais, a drenagem das águas pluviais, os usos do solo, entre outros, são indispensáveis para atrair a população e para garantir a qualidade da paisagem urbana. A presença da vegetação contribui, particularmente, para garantir o bem-estar humano e favorecer o desempenho ambiental.

- Para Caldeira (2007), as praças têm desenvolvido, na cultura ocidental, um papel referencial: toda cidade possui uma praça que se destaca como palco de eventos históricos, espaço agregador, local de convergência, símbolo urbano. A praça é uma tipologia comum às culturas urbanas de origem europeia ocidental, associada à imagem de espaço livre cercado de edificações. Sustenta um patrimônio rico em história e tradição, configurando-se como um espaço com elevado conteúdo simbólico.

- De acordo com Lamas (1993), a praça é um componente morfológico das cidades ocidentais que, distinguindo-se de espaços que são o resultado acidental do alargamento ou da confluência de traçados, caracteriza-se pela organização espacial e pela intencionalidade de desenho. A este propósito, Lamas (1993) define a praça como o lugar público do encontro, da permanência, do comércio e da circulação, que funciona como palco para acontecimentos festivos, comemorações e manifestações, onde a arquitetura possui destaque. Para o autor, a praça possui função de convívio, geralmente está inserida no tecido urbano com área aproximada à de uma quadra, e contém expressiva cobertura vegetal, mobiliário urbano e infraestrutura.

Nas praças, o perímetro é, geralmente, encerrado pelas quatro fachadas do conjunto edificado envolvente que, em seu espaço interior, contêm esta praça, e seus elementos constituintes. De acordo com Zevi (2011), o conteúdo - no caso, da praça -, será este espaço interior, que nos rodeia e inclui. Para o desenvolvimento de um projeto de praça, o que deve ser analisado é o valor daquilo que ela contém. O seu projeto deverá objetivar a ordenação e a orientação no espaço, a partir de arranjos volumétricos e espaciais, que denotarão distintas ambiências, ao percorrerem-se os seus subespaços. A fim de que o projeto resulte em satisfatório, resulta identificar quais serão os elementos constituintes do projeto.

Nesta pesquisa, a partir das informações elencadas, conceitua-se o termo praça como o espaço público urbano, com características de convergência e centralidade, que está destinado às práticas de sociabilidade, e no qual está prevista uma porcentagem significativa de áreas verdes, destinada a cumprir funções ecológicas. Com base nos pressupostos apresentados e, a partir de um conjunto de autores, nesta pesquisa elencados, realizou-se a sistematização de conceitos que definem a qualidade espacial de praças, e que serão apresentados a seguir, em cinco principais tópicos: 1) edificações; 2) rotas de circulação; 3 ) elementos urbanos; 4) atividades; 5) ajardinamentos (SITTE, 1992; MARCUS, FRANCIS, 1998; MOURTHÉ, 
1998; BACKES, 2010; ABBUD, 2006; VAZ, 2010; JOHN, REIS, 2010; LYNCH, 2011) - ilustrados nesse texto pelas Figuras 1 a 5.

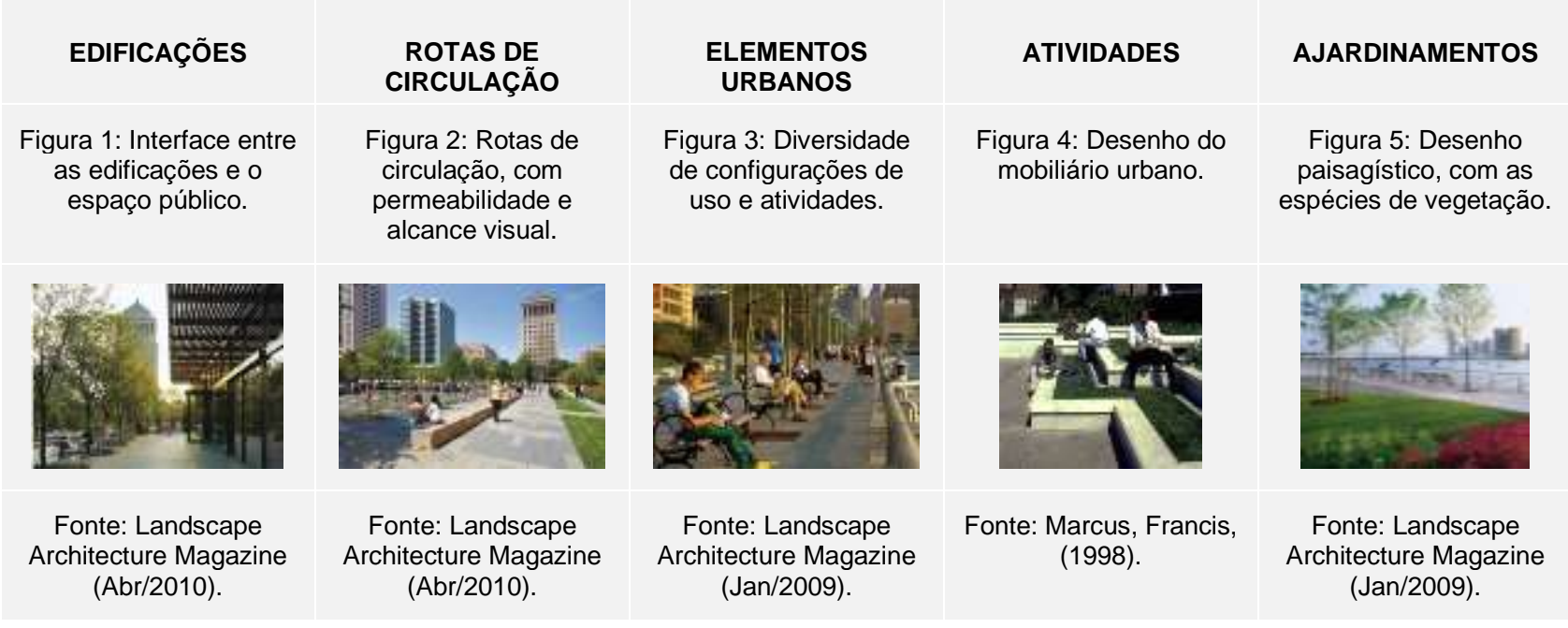

\section{Edificações}

Quanto maior a nitidez dos limites espaciais da praça, mais fácil será o deslocamento por entre os seus espaços e a clareza de orientação nos percursos. A nitidez dos limites espaciais dá-se a partir da diferenciação de seu perímetro, em relação ao entorno urbano, ou do contraste entre superfície, forma e porte das edificações que a circundam $(\mathrm{LYNCH}, 2011)$. É interessante que as fachadas das edificações não somente estejam posicionadas em alinhamento, mas também se situem próximas umas às outras, garantindo a compacidade do conjunto edificado. A compacidade é um atributo importante, pois definirá um espaço em negativo, no tecido urbano, cuja geometria definirá a forma da praça, transformando-a em um ponto nodal, uma centralidade.

Quando a praça não estiver diretamente integrada às vias do entorno - circundada por elas, em todos os seus lados -, a relação que se estabelecerá com os lotes, em seu perímetro, tem de ser considerada. É interessante de que hajam edificações voltadas à praça, possibilitando a integração física e visual, entre os espaços públicos e os privados. O alinhamento entre estas edificações pode contribuir para a identificação dos limites espaciais da praça. A fim de garantir a clareza de acessos às edificações, estes podem estar alocados em proximidade. A hierarquia de uma edificação, em relação às demais, funcionará como referência espacial, para identificar-se a praça, no tecido urbano. A hierarquia pode ser definida por sua dimensão e forma, e pela localização diferenciada, em relação às demais. As formas que possuem clareza e simplicidade, tanto em sentido geométrico, quanto na delimitação de suas partes, serão mais facilmente apreendidas (LYNCH, 2011).

A centralidade da praça será reforçada pela diversidade de usos, pela intensidade de frequentação e por sua integração às vias do entorno urbano. É importante observar que, quanto menor o perfil das vias que a circundam, maior a possibilidade de integração do conjunto edificado, com a praça. A inexistência de barreiras físicas (vias, ciclovias, faixas de estacionamento), facilitará a franca acessibilidade à praça. Se houverem vias, a existência de sinaleiras e faixas de segurança facilitará a conectividade do entorno urbano. É interessante que sejam considerados, nas rotas de circulação da praça, pisos táteis e sinalização para a acessibilidade universal. Se os pisos estiverem nivelados, a circulação de pedestres dar-se-á sem barreiras à acessibilidade e à livre circulação.

Os acessos às edificações, no perímetro da praça, serão um local significativo para encontros, determinando uma maior concentração de atividades. Eles podem estar nivelados à praça, ou possuir acessibilidade universal. $\mathrm{Na}$ interface entre os espaços públicos e os privados, pode-se considerar ajardinamentos e aberturas bem dimensionadas. As áreas delimitadas pelas paredes das edificações podem servir de anteparo para os ajardinamentos e definir espaços de permanência, com ou sem beirais. Se a finalidade for a permeabilidade visual, as aberturas podem ser posicionadas onde as pessoas costumam circular, parar e observar o movimento. Os ajardinamentos, em frente às edificações, possibilitarão uma transição suave, paisagística e de amortecimento sonoro, entre os espaços públicos e os privados (MARCUS, FRANCIS, 1998). Eles provêm oportunidades de encontro, lazer e recreação, e configuram áreas externas, nas quais pode-se permanecer, por períodos prolongados. Quanto mais os 
usuários frequentam a praça, mais familiarizados a ela se tornam, aumentando-se o senso de identidade e pertencimento.

\section{Rotas de circulação}

A circulação de pedestres é o principal atributo a determinar a percepção territorial na praça. Ao projetar o acesso principal, deve-se considerar a conectividade com as principais vias do entorno urbano. É fundamental que os acessos possuam fácil acessibilidade e as rotas de circulação apresentem opções de estar e permanência ao longo dos caminhos. O projetista pode tirar partido do potencial paisagístico do lote, buscando a variação de ângulos ao longo do caminho, a fim de estimular a atenção dos usuários, aos elementos da paisagem (ABBUD, 2006). As rotas de circulação devem prever caminhos para pedestres, bicicletários, áreas de recreação e espaços de convívio, com funções de uso diversificadas, favorecendo a sociabilidade. Os estacionamentos podem ser estrategicamente localizados, facilitando as questões de acessibilidade à praça.

As rotas de circulação serão identificadas a partir de ligações simples (ambiente por ambiente), ou de sequencias espaciais. As rotas mais indicadas são as que margeiam a vegetação, pois facilitam a manutenção, e evitam cortar o espaço destinado às áreas verdes (BACKES, 2004). Sua forma será adequada, se for compatível com o processo de caminhar: inicialmente, definem-se os pontos nodais para, então, estabelecer as conexões. Estes pontos nodais, circunscritos na praça, serão referenciais para a organização espacial. Podem ser tratados não apenas como espaços de passagem, mas também como locais de permanência. A concentração de atividades, nos pontos nodais, estimulará as pessoas a se envolverem com o que está acontecendo, possibilitando a permanência.

Os pontos nodais devem ser projetados para garantir a ampla visibilidade entre os subespaços da praça, contribuindo para a sensação de segurança. O predomínio de um ponto nodal sobre os demais, em decorrência de sua distinção, tamanho ou centralidade, resulta na facilidade de apreensão deste espaço, em relação aos demais (LYNCH, 2011). Os espaços sem barreiras à acessibilidade e à livre circulação garantem a permeabilidade espacial. O alcance visual, entre os espaços, facilitará a identificação dos percursos, através de transparências ou visuais panorâmicas ( $\mathrm{LYNCH}, 2011)$. Uma área contínua e sem obstáculos permite ao usuário a condição de fazer-se presente, estabelecendo contato com outros, e o seu distanciamento, quando necessário ou desejável (VAZ, 2010).

\section{Atividades}

De acordo com Sitte (1992), quando se estabelece uma praça, ela ocupa um lugar dentro da malha urbana que, inicialmente, é considerado um vazio urbano. No momento em que as pessoas passam a usufruir desta praça, ali se estabelece um espaço, um sentido de permanência. A permanência será resultado das condições de conforto e da existência de elementos urbanos, que preservem a escala humana, em uma configuração que contribua para a interação social. Também será resultado da frequência de usos e atividades. A regularidade na frequentação estabelecerá padrões de uso e comportamento, nos quais os usuários, familiarizados com o lugar, contribuirão para a sua conservação (MARCUS, FRANCIS, 1998).

Tais características podem ser reforçadas pelo ordenamento dos espaços, pela disposição do mobiliário e pela proximidade física entre as pessoas. Também resultarão de atributos que estimulem as relações de vizinhança, e os contatos que surgem espontaneamente. Lynch (2011) afirma que as pessoas tendem a preferir locais onde se sintam protegidas, onde possam observar o movimento, e tendem a escolher, para permanecer, aqueles locais onde há algum elemento que Ihes sirva de apoio ou referência. A fim de aumentar as possibilidades de interação, sugere-se a distribuição de locais para sentar ao ar livre, voltados para onde ocorrem as atividades, dentre as quais podem ser: interagir em grupos, praticar exercícios físicos, realizar apresentações artísticas, fazer refeições, conversar, namorar, ler, brincar, passear, contemplar, descansar, locomover-se, entre outros. Os espaços para estas atividades consideram (MARCUS, FRANCIS, 1998):

- Gramados, ajardinamentos e caminhos, com distintas disposições espaciais;

- Gramados a pleno sol, e áreas parcialmente ensolaradas, para permanência;

- Bancos conformando ilhas espaciais, nas bordas dos espaços, ou ao redor de árvores expressivas.

Por fim, as praças de grandes dimensões podem ficar vazias se não houver algo que estimule a permanência, uma vez que há uma correlação direta entre as dimensões da praça e a presença de pessoas. Sugere-se, como parâmetro, uma área de 14 a $28 \mathrm{~m}^{2} /$ pessoa, bem como a alocação de bancos, 
árvores, esculturas, postes, fontes e outros elementos urbanos, nos principais espaços da praça (LYNCH, 2011). Ao projetar estes espaços, sugere-se considerar o seu posicionamento fora das principais rotas de circulação. Eles podem estar alocados em gramados (ao ar livre); em áreas distantes do tráfego de veículos ou de estacionamentos; em áreas adjacentes às rotas de circulação secundárias; em pátios semiabertos ou terraços; em locais próximos às paredes das edificações ou localizados sob as copas das árvores e nas extremidades de caminhos (MARCUS, FRANCIS, 1998).

\section{Elementos urbanos}

Os elementos urbanos são todos os objetos em diferentes escalas, componentes da paisagem urbana, implantados no espaço público com a finalidade de auxiliar na prestação de serviços, na segurança, na orientação e no conforto dos usuários (JOHN, REIS, 2010). Os elementos urbanos, em uma praça, podem ser bancos e assentos, mesas, bebedouros, espelhos d'água, fontes, obras de arte, palco ou anfiteatro, telefones públicos, lixeiras para coleta seletiva, entre outros (MOURTHÉ, 1998). O seu desenho estará associado a aspectos compositivos que influirão nas formas de apropriação dos espaços. Estes elementos devem ser propostos de modo a não obstruir as rotas de circulação, permitindo o contato espontâneo - ou programado - entre os usuários, bem como a sua permanência.

Dentre os elementos urbanos, o mobiliário possui grande importância, com funções de uso específicas, que contribuem para tornar a permanência mais segura e confortável. A relação entre os diferentes tipos de mobiliário urbano presentes nos espaços abertos pode ser considerada fator que interfere na imagem que as pessoas têm de suas cidades (JOHN, REIS, 2010). O desenho do mobiliário, considerando-se uma disposição integrada a outros elementos da paisagem, garantirá que cada espaço seja um local de estímulo às atividades, sejam elas de encontro, lazer ou recreação. A sua distribuição, em pontos equidistantes da praça, garantirá com que não hajam espaços subutilizados e, acima de tudo, que os usuários possam usufruir, em qualquer estágio do percurso, de locais como ponto de parada ou permanência (Figura 04).

Ainda com relação ao desenho do mobiliário, é interessante que os bancos possuam assentos confortáveis e encosto, e permitam a sua utilização individual, ou em grupos. A forma do mobiliário também deve ser considerada: os bancos em forma circular oferecem, por um lado, uma disposição voltada ao centro da praça (côncava) e, por outro, uma disposição voltada aos espaços circundantes (convexa). Nas praças, a previsão de mesas e bancos, com ergonomia adequada, será um estímulo à permanência. Pode-se considerar a alocação do mobiliário em contiguidade aos ajardinamentos, a fim de garantir a permanência (temporária ou prolongada) dos usuários, próximos a elementos naturais. Os bancos e assentos podem, ainda, ser posicionados nas bordas dos ajardinamentos ou em torno de árvores particularmente expressivas, com assentos que conformem ilhas espaciais (MARCUS, FRANCIS, 1998) - conforme ilustra a Figura 05.

O desenho do mobiliário urbano contribuirá para a qualidade espacial. Outros elementos (tais como arte pública, iluminação, etc.) darão suporte às atividades que nela ocorrerão. Os elementos de arte pública, tais como esculturas e obras de arte, possibilitam, a partir de seus atributos formais, a qualificação dos espaços. É interessante que estejam posicionados nos pontos nodais, facilitando a orientação nos percursos. A iluminação melhora qualitativamente as ambiências, ao destacar determinados elementos na paisagem. Se bicicletas forem utilizadas, devem-se prever bicicletários. Uma fonte, em um ponto focal, pode receber destaque. Podem-se ainda prever, em seu perímetro, estabelecimentos comerciais que possibilitem a permanência.

\section{Ajardinamentos}

O último atributo, de grande importância, para a qualidade espacial, será a presença de vegetação. Nas praças, a vegetação desempenhará funções ambientais, e poderá agregar qualidade paisagística, aos espaços existentes. Estudos realizados por Kaplan (1998) atestam que a vegetação atua sobre o comportamento humano, e evidenciam o poder de recuperação, concentração e alívio do estresse, que é proporcionado pelo contato humano com elementos naturais. Beneditto Abbud (2006), em seu livro Criando paisagens: guia de trabalho em arquitetura paisagística, busca transmitir métodos e técnicas relativos à arquitetura da paisagem, considerando prioritária a utilização de vegetação para a criação das paisagens. De acordo com o autor, embora este não seja um livro voltado aos aspectos teóricos e conceituais da disciplina paisagística, ele traz um conjunto de ações adequadas ao paisagismo urbano (Figura 07).

Um dos atributos, que envolvem a presença de vegetação na praça, trata-se dos condicionantes físicos nela incidentes (forma dos espaços, largura dos passeios, distribuição de áreas verdes, homogeneidade dos 
ajardinamentos). Na seleção de espécies, consideram-se as características dos espaços, para selecionarse aquelas mais indicadas, a fim de garantir que se adaptem ao ecossistema local. Inicialmente, deve-se projetar o arranjo volumétrico, a composição de cores e a disposição dos estratos vegetais. É importante observar as questões de acessibilidade, facilitando a manutenção e a utilização dos espaços. De acordo com Abbud (2006), os arranjos espaciais poderão ser organizados, horizontalmente, pelos planos de pisos, verticalmente pelas superfícies de vedação e, no plano de teto, pelo limite das copas de vegetação. Nesta organização espacial, é fundamental que os projetistas considerem os benefícios formais e funcionais de cada espécie, objetivando a um desenho paisagístico que favoreça a qualidade espacial (Figura 08).

O zoneamento das espécies iniciará pela definição de um plano de massas, onde será estudada a configuração da futura paisagem, considerando-se a forma, a cor, a textura, o aroma, o volume e o ritmo das espécies (BACKES, 2010). A forma dos ajardinamentos atuará como um elemento compositivo, denotando distintas ambiências, ao percorrerem-se os espaços. Na seleção e na distribuição das espécies, considera-se que estas estejam associadas a pontos de parada, ou dispostas ao longo dos caminhos e espaços de estar existentes. Sugere-se um zoneamento gradativo, a partir da intensidade de usos e de frequentação. O zoneamento poderá definir-se por espécies isoladas, forrações, maciços arbustivos ou conjuntos arbóreos (ABBUD, 2006). Na seleção de espécies, considera-se que a vegetação cumpra cinco funções: como marcação de eixos, enquadramentos, conexões espaciais, pontos focais e barreiras físicas (ABBUD, 2006, BACKES, 2010; MARCUS, FRANCIS, 1998), resumidamente detalhadas no Quadro 1, a seguir.

Quadro 1: Plano de massas, considerando as funções da vegetação.

\section{FUNÇÕES DA VEGETAÇÃO}

\begin{tabular}{|c|c|}
\hline \multicolumn{2}{|r|}{ FUNÇOES DA VEGE IAÇAO } \\
\hline $\begin{array}{l}\text { Marcação de } \\
\text { eixos }\end{array}$ & $\begin{array}{l}\text { Projetar colunatas de palmeiras, ou espécies arbóreas pontuais, cujo espaçamento e } \\
\text { alinhamento definirão a marcação de eixos visuais e percursos. Quanto maior a verticalidade da } \\
\text { vegetação, maior a sua distinção visual, na percepção global da paisagem. Quanto maior a } \\
\text { horizontalidade da vegetação, melhor a conformação de ambiências, sob as copas. }\end{array}$ \\
\hline Enquadramentos & $\begin{array}{l}\text { Definir enquadramentos através de aberturas estratégicas nos maciços de vegetação, realçando } \\
\text { paisagens, ou visuais específicas. Na definição destes enquadramentos, a permeabilidade será } \\
\text { um importante atributo e ser considerado, está relacionado à densidade das copas, bem como } \\
\text { à altura e ao porte da vegetação: quanto mais próximas e baixas, maior a tendência de a } \\
\text { vegetação obstruir as visuais, na linha do observador; quanto mais altas, maior a } \\
\text { permeabilidade visual. Assim, conjuntos arbóreos, com copas altas, e maciços arbustivos, de } \\
\text { folhagens pouco densas, gerarão distintos níveis de permeabilidade, permitindo, ou não, os } \\
\text { enquadramentos de paisagem. }\end{array}$ \\
\hline $\begin{array}{l}\text { Conexões } \\
\text { espaciais }\end{array}$ & $\begin{array}{l}\text { Configurar espaços de lazer, ambientes de estar e pontos de encontro contíguos às edificações. } \\
\text { Sua composição, com espécies de vegetação diversificadas, contribuirá para definir as } \\
\text { ambiências da praça. Complementarmente, podem ser propostas áreas cobertas e abertas, ou } \\
\text { elementos construídos, que integrem as esferas de uso entre os espaços públicos e privados } \\
\text { (galerias, marquises, arcadas, pergolados, decks e superfícies com pavimentação diferenciada). }\end{array}$ \\
\hline Pontos focais & $\begin{array}{l}\text { Dispor espécies de vegetação em pontos de encontro, ao final de caminhos para arrematá-los, } \\
\text { ou como referências de localização, nas rotas de circulação. Quanto mais vistosas as espécies, } \\
\text { melhor a definição de pontos focais. Complementarmente, utilizar a iluminação como estratégia } \\
\text { de destaque. }\end{array}$ \\
\hline Barreiras físicas & $\begin{array}{l}\text { Propor cercas vivas ou maciços arbustivos que demarquem, sem esconder, paisagens ou } \\
\text { visuais importantes. Se possuírem altura acima da linha do observador, estes elementos } \\
\text { também funcionam como barreiras visuais. Neste sentido, outros recursos construídos podem } \\
\text { ser utilizados, tais como muros, grades, escadarias ou desníveis. }\end{array}$ \\
\hline
\end{tabular}

Fonte: Abbud (2006), Backes (2010), Marcus e Francis (1998), dados retrabalhados pela autora.

O plano de massas poderá considerar, ainda, uma transição gradativa entre a vegetação e a arquitetura, bem como o agrupamento de espécies por similaridade, reforçando as suas características formais. Assim, a vegetação poderá definir a forma dos espaços, demarcar eixos e visuais, exercer a função de barreira física ou de quebra-ventos, promover sombreamento, entre outros. As aberturas das edificações, no perímetro da praça, caso existentes, possibilitarão emolduramentos da ampla paisagem. Na praça, o caráter 
Ecker, V.

ornamental dos ajardinamentos colocará em evidência a plasticidade da vegetação, no desenho paisagístico.

\section{CONCLUSÃO}

As relações entre as pessoas e os espaços, além da evidente correspondência física que forçosamente entre eles se estabelece, tem um forte componente psicológico. As pessoas se sentem melhor em certos espaços. Ou, em outras palavras, certos espaços se distinguem dentro do espaço maior onde se situam as pessoas e, ao se distinguirem, se tornam percebidos de maneira diferente. Em geral, são percebidos como espaços detentores de qualidades (CASTELLO, 2005, p. 15).

Em muitas cidades, a praça proporciona uma ruptura no tecido urbano, configurando um ponto nodal, para as práticas de sociabilidade. Devido ao seu caráter integrativo, ela define-se como um espaço de convergência e centralidade, que tende a concentrar usos, funções e atividades, e a exercer o papel de centralidade urbana. Por sua importância, é considerada um espaço referencial.

Nesta pesquisa, a partir das informações elencadas, conceituou-se o termo praça como o espaço público urbano, com características de convergência e centralidade, que está destinado às práticas de sociabilidade, e no qual está prevista uma porcentagem significativa de áreas verdes, destinada a cumprir funções ecológicas. Na pesquisa também objetivou-se identificar e sistematizar conceitos, que foram selecionados a partir da abordagem de diversos autores, e organizados em torno de cinco principais tópicos: 1) edificações; 2) rotas de circulação; 3) atividades; 4) elementos urbanos; 5) ajardinamentos.

Acredita-se que as praças, enquanto locus da sociabilidade, constituem espaços referenciais para a qualidade de vida dos habitantes às cidades. Nelas, a presença de elementos naturais, ou da direta relação entre eles e o ambiente construído, qualificam o ambiente urbano, não só do ponto de vista de seu desempenho ambiental, mas também do benefício psicológico que promovem. Embora a pesquisa apresente informações sucintas, o tema não se esgota aqui, e certamente outros detalhes importantes, ao longo de seu desenvolvimento, poderiam ser citados, que não estão apresentados. A partir das informações elencadas, entende-se que o desenho de praças é um importante referencial a ser considerado, com vistas à qualidade da paisagem urbana.

\section{REFERÊNCIAS}

ABBUD, B. Criando paisagens: guia de trabalho em Arquitetura Paisagística. São Paulo: Editora SENAC, 2006.

ARENDT, H. A condição da vida humana. Rio de Janeiro: Editora Forense Universitária, 2007. (Texto original de 1958).

BACKES, M. A. Princípios do Paisagismo Ecológico. Curso Modular "Paisagismo Regenerativo" - apostilas diversas (não publicado). Nova Petrópolis-RS, 2004.

BACKES, M.A. Curso Completo de Jardinagem e Paisagismo - apostilas diversas (não publicado). Nova Petrópolis-RS, 2010.

BORJA, J.; MUXI, Z. El espacio público, ciudad y ciudadanía. Barcelona: Ed. Península, 2000.

CALDEIRA, J. M. A praça brasileira. Trajetória de um espaço urbano: origem e modernidade. Tese (Doutorado). Instituto de Filosofia e Ciências Humanas, Universidade de Campinas, 2007.

CARR, S.; FRANCIS, M.; RIVLIN, L. G.; STONE, A.M. Public space. Davis: University of California, 1995.

CASTELLO, L. Repensando o lugar no projeto urbano: variações na percepção de lugar na virada do milênio (19852004). Tese (Doutorado). Programa de Pesquisa e Pós-Graduação em Arquitetura, Universidade Federal do Rio Grande do Sul, 2005.

FERREIRA, A. B. H. Novo dicionário da Língua Portuguesa. Rio de Janeiro: Ed. Nova Fronteira, 1986.

GEHL, J. Cities for people. Washington: Island Press, 2010.

HABERMAS, J. Mudança estrutural da esfera publica: investigações quanto a uma categoria da sociedade burguesa. Rio de Janeiro. Tempo Brasileiro, 1984.

JACOBS, J. Morte e vida de grandes cidades. São Paulo: Martins Fontes, 2001.

JOHN, N.; REIS, A. T. Percepção, estética e uso do mobiliário urbano. Gestão \& Tecnologia de Projetos, v. 5, n. 2, novembro/2010. 
Ecker, V.

LAMAS, J. M. R.G. Morfologia Urbana e Desenho da Cidade. Lisboa: Fundação Calouste Gulbenkian, 1993.

LANDSCAPE MAGAZINE, v. 99, n. 1. Washington D.C.: American Society of Landscape Architects, January 2009.

LANDSCAPE MAGAZINE, v. 100, n. 4. Washington D.C.: American Society of Landscape Architects, April 2010.

LYNCH, K. A Imagem da Cidade. São Paulo: WMF / Martins Fontes, 2011. (Texto original de 1960).

MAGRO, M.L. Os espaços externos do Campus I da Universidade de Passo Fundo: a análise da percepção dos usuários e de suas referências. Dissertação (Mestrado). Programa de Pós-Graduação em Engenharia Civil. Universidade Federal do Rio Grande do Sul. Porto Alegre/RS, 2006.

MARCUS, C.C.; FRANCIS, C. People places: design guidelines for urban open space. Nova lorque: John Wiley, 1998.

MARX, M. Cidade no Brasil - Terra de quem? São Paulo: EDUSP/Livraria Nobel S.A., 1991.

MASCARÓ, L. Ambiência Urbana. Porto Alegre: +4 Editora, 1996.

MASCARÓ, J. L. Infraestrutura da Paisagem. Porto Alegre: +4 Editora, 2007.

MENEZES, F. M. Projeto urbano e criação de espaços públicos: cidade pedra branca na grande Florianópolis. Dissertação (Mestrado). Pós-Graduação em Urbanismo, História e Arquitetura da Cidade, Universidade Federal de Santa Catarina, Florianópolis, 2013.

MOURTHÉ, C. Mobiliário Urbano. Rio de Janeiro: 2AB, 1998.

OLIVEIRA, L. A. Padrões espaciais na morfologia urbana na llha de Santa Catarina: diálogos entre o local e o global. In: G. P. A. SILVA; L. A. OLIVEIRA (Orgs.). Arquitetura da cidade contemporânea: sobre raízes, ritmos e caminhos. Florianópolis: Editora da UFSC, 2013.

REIS FILHO, N. G. Notas sobre urbanização dispersa e novas formas de tecido urbano. São Paulo: Via das Artes, 2006. SENNETT, R. O declínio do homem público - as tiranias da intimidade. São Paulo: Companhia das Letras, 1993. (Texto original de 1970).

SIMMEL, G. Questões fundamentais da sociologia: indivíduo e sociedade. Rio de Janeiro: Jorge Zahar Ed., 2006. (Texto original de 1917).

SITTE, C. A construção das cidades segundo seus princípios artísticos. São Paulo: Ática, 1992. (Texto original de 1889).

TENÓRIO, G. S. Ao desocupado em cima da ponte - Brasília, arquitetura e vida pública. Tese (Doutorado). Programa de Pós-Graduação em Arquitetura e Urbanismo, Universidade de Brasília, 2012.

VAZ, N. P. La place publique comme espace de communication - La place publique centrale de Florianópolis au Brésil et la place parisienne. Saarbrücken: Editions Universitaires Europeennes (EUE), 2010.

ZEVI, B. Saber ver a arquitetura. São Paulo: Martins Fontes, 2011. (Texto original de 1959).

NOTA DO EDITOR ( ${ }^{*}$ ) O conteúdo do artigo e as imagens nele publicadas são de responsabilidade do(s) autor(es). 